\title{
Ki-67 immunolabeling in pre-malignant lesions and carcinoma of the prostate. Histological correlation and prognostic evaluation
}

\author{
E. Muñoz, ${ }^{*}$ F. Gómez, ${ }^{\circ}$ J.I. Paz, ${ }^{*}$ I.Casado, ${ }^{\circ}$ J.M. Silva, ${ }^{\S}$ M.T. Corcuera, ${ }^{\circ}$ M. J. Alonso ${ }^{\circ}$ \\ *Department of Cellular Biology and Pathology, University of Salamanca; ${ }^{\circ}$ Department of Pathology, \\ Institute of Health Carlos III, Madrid; 's Department of Urology, University of Salamanca, Spain
}

(C)2003, European Journal of Histochemistry

The antigen Ki-67, which is associated with cell proliferation, has been demonstrated to be useful in predicting the development of human tumors. The objective of this study was to evaluate the prognostic utility of this biomarker in pre-malignant and malignant lesions of the prostate. A total of 162 prostate biopsies taken from patients diagnosed for benign prostatic hyperplasia $(\mathrm{BPH}, \mathrm{n}=49$ ), low grade prostatic intraepithelial neoplasia (LGPIN, $n=53$ ), high grade prostatic intraepithelial neoplasia (HGPIN, $n=25$ ) and carcinoma (CAR, $\mathrm{n}=35$ ), were studied. Immunohistochemistry for Ki-67 was carried out on all the samples and the number of labeled cells was semi-quantitatively evaluated (weak, moderate or intense). In the non-invasive lesions, the presence of Ki-67positive cells in the luminal layer of the epithelium was evaluated qualitatively as positive or negative. The correlation between the immunolabeling for Ki-67 and the histological diagnosis showed highly significant differences between BPH and CAR, LGPIN and CAR and HGPIN and CAR, with no significant differences being found among the other groups. Analysis of the immunolabeling in luminal cells of non-invasive lesions showed an increase in accordance with the increase in the degree of histological lesion, the greatest percentage being obtained in the HGPIN lesions (88.0\%), with significant differences among all the groups. Bearing in mind that Ki-67 is a prognostic biomarker for cell proliferation, our results demonstrating the immunolabeling of Ki-67 in the luminal compartment of non-invasive lesions having the potential to evolve to malignancy, may have prognostic implications.

Correspondence: Dra. Elisa Muñoz Torres, Department of Cellular Biology and Pathology, Faculty of Medicine, University of Salamanca, Avda. Campo Charro s/n. 37007 Salamanca, Spain. Phone: international +34.923.294400. Ext: 1859. Fax: international +34.923.294549. E-mail: emuto@gugu.usal.es

Key words: Ki- 67, prostate, pre-malignant lesions, carcinoma, immunohistochemistry

Paper accepted on January 31, 2003.

European Journal of Histochemistry

2003; vol. 47 issue 2 [Apr-Jun]:123-128
The notion of pre-malignant lesions and the sequence of morphological changes that culminate in carcinoma has been well established in some organs, such as the breast (Lowell, 1987; Tavassoli et al., 1990), cervix (The $1988 \mathrm{Be}-$ thesda system, 1989), skin (Frankel, 1987; Rywlin, 1988), etc. Indeed, the knowledge of these lesions with pre-cancerous potential has led to therapeutic decisions being taken based on the morphological identification of the pre-malignant lesions in some of these organs.

Despite the fact that carcinoma of the prostate is the most common cancer in the male (Boring et al., 1993) and a myriad of studies having been carried out, knowledge about carcinogenesis of the prostate has still not been completely analyzed. In general, it is accepted that prostatic intraepithelial neoplasia (PIN), or duct-acinar dysplasia, is probably the most important precursor lesion of invasive cancer. These lesions can often be recognized in the prostate before the development of an invasive carcinoma (Cohen et al., 2000). Bearing in mind that the best way to combat them is by early diagnosis, a full knowledge of the lesions with potential for malignant evolution of the prostate is extremely important. The study of prognostic factors or biomarkers in these lesions and their standardization could help to better understand the evolutionary sequence of the phenomena involved in prostate carcinogenesis.

The expression of the human protein $\mathrm{Ki}-67$ is associated with cell proliferation. During interphase, the antigen can only be detected within the nucleus, whereas in mitosis, the majority of the protein is trans-located to the surface of the chromosomes. The fact that $\mathrm{Ki}-67$ protein is present during all the active phases of the cell cycle (GI, S, G2 and mitosis), and absent from the GO phase, has made it an excellent marker for determining the growth fraction of a determined cell population (normal or tumoral) (Scholzen and Gerdes, 2000). Further- 
more, the fraction of tumor cells positive for $\mathrm{Ki}-67$ (labeling index) has been correlated with the clinical course, recurrences and survival in prostate cancer (Aaltomaa et al., 1997; Borre et al., 1998; Bettencourt et al., 1996; Bubendorf et al., 1996; Moul et al., 1996; Keshgegian et al., 1998; Bai et al., 1999; Brown et al., 1996; Cher et al., 1996; Hepburn et al., 1995; Stapleton et al., 1998), suggesting that $\mathrm{Ki}-67$ can be used as a prognostic factor in the monitoring of these patients.

The purpose of this study was to evaluate the presence of $\mathrm{Ki}-67$ in prostate lesions with potential for malignant transformation and carcinoma, its correlation with the distinct histological diagnoses and its prognostic utility, evaluating its presence in the different epithelial layers.

\section{Materials and Methods}

We studied one hundred and sixty-two prostate biopsies from patients who came to the urological surgery clinic complaining of prostate symptoms, PSA serum levels $>3 \mathrm{ng} / \mathrm{L}$ and doubtful or positive rectal exploration.

Trans-urethral biopsy was performed, obtaining 3-5 cylinders, which were fixed in 10\% formaldehyde, routinely processed for light microscopy and stained with haematoxylin-eosin. The lesions were histologically classified as: benign prostate hyperplasia (BPH), low grade prostate intraepithelial neoplasia (LGPIN), high grade prostate intraepithelial neoplasia (HGPIN) and Carcinoma (CAR), grading these in accordance with Gleason's score system.

Sections from each biopsy specimen were subjected to immunohistochemistry for $\mathrm{Ki}-67$ using an anti-Ki-67 antibody (DAKO Corp., dilution 1:100), in an automatic immunohistochemistry system (NEXES, Ventana), based on the avidin-biotin complex with horse-radish peroxidase as a label and $\mathrm{H}_{2} \mathrm{O}_{2}$-diaminobenzidine as substrate-chromogen. The processing of the sample, prior to incubation with the primary antibody, included antigenic unmasking by heating in citrate buffer at $\mathrm{pH}$ 6.0, for 4 min at $120^{\circ} \mathrm{C}$.

The percentage of cells positive for $\mathrm{Ki}-67$ was scored semi-quantitatively, according to the number of labeled cells observed, as weak (marked as + ), $<25 \%$ of labeled cells, moderate (marked as ++ ), $25-75 \%$ of labeled cells, and intense (marked as $+++),>75 \%$ of labeled cells. Moreover, in the non- invasive lesions, the immunolabeling of $\mathrm{Ki}-67$ in the luminal cells was quantitatively scored as positive (some cells immunolabeled) and negative (no immunolabeled cells). This evaluation was carried out exclusively in the zones of prostate epithelium that presented the lesion diagnosed in the original biopsy.

Significance between the positivity observed and the distinct histological diagnoses were analyzed statistically using the chi-square test. Differences were considered statistically significant at $p<0.05$.

\section{Results}

In the histological study were diagnosed 49 cases as BPH (30.2\%), 53 cases as LGPIN (32.7\%), 25 cases as HGPIN (15.4\%) and 35 cases as CAR $(21.6 \%)$.

Semi-quantitative evaluation of the immunolabeling for $\mathrm{Ki}-67$ demonstrated that the majority of the BPH lesions $(85.7 \%)$, LGPIN $(81.1 \%)$ (Figure 1-A) and HGPIN (72.0\%), (Figure 1-B), presented weak positivity $(+)$. On the other hand, the majority of the CAR $(62.9 \%)$ presented moderate positivity (++) (Figure 1-C) and $14.3 \%$ intense positivity (Figure 1-D).

Gleason's score for the CAR ranged between 4 and 9 , the greatest percentile $(34.3 \%)$ having a score of 6 . We did not find significant differences between the immunolabeling for $\mathrm{Ki}-67$ and Gleason's score.

The results for each of the histological lesions, evaluated without taking into account the immunolabeled cellular compartment, are presented in Table 1. The correlation between the immunolabeling for $\mathrm{Ki}-67$ and the histological diagnosis showed statistically significant differences between BPH and CAR $(p<0.001)$, LGPIN and CAR $(p<0.001)$ and HGPIN and CAR $(p<0.001)$; significant differences were not found among the other groups.

The qualitative evaluation of the presence of $\mathrm{Ki}$ 67-positive cells in the luminal layer of the prostate epithelium in non-invasive lesions is shown in Table 2. It can be seen that the percentage of positivity for $\mathrm{Ki}-67$ in the luminal compartment increases in accordance with the increase of the grade of histological lesion, the greater percentage being obtained in the HGPIN lesions (88.0\%) (Figure 1$B)$. Differences were statistically significant between BPH and LGPIN $(p<0.02), B P H$ and HGPIN $(p<0.001)$ and between LGPIN and HGPIN $(p<0.001)$. 

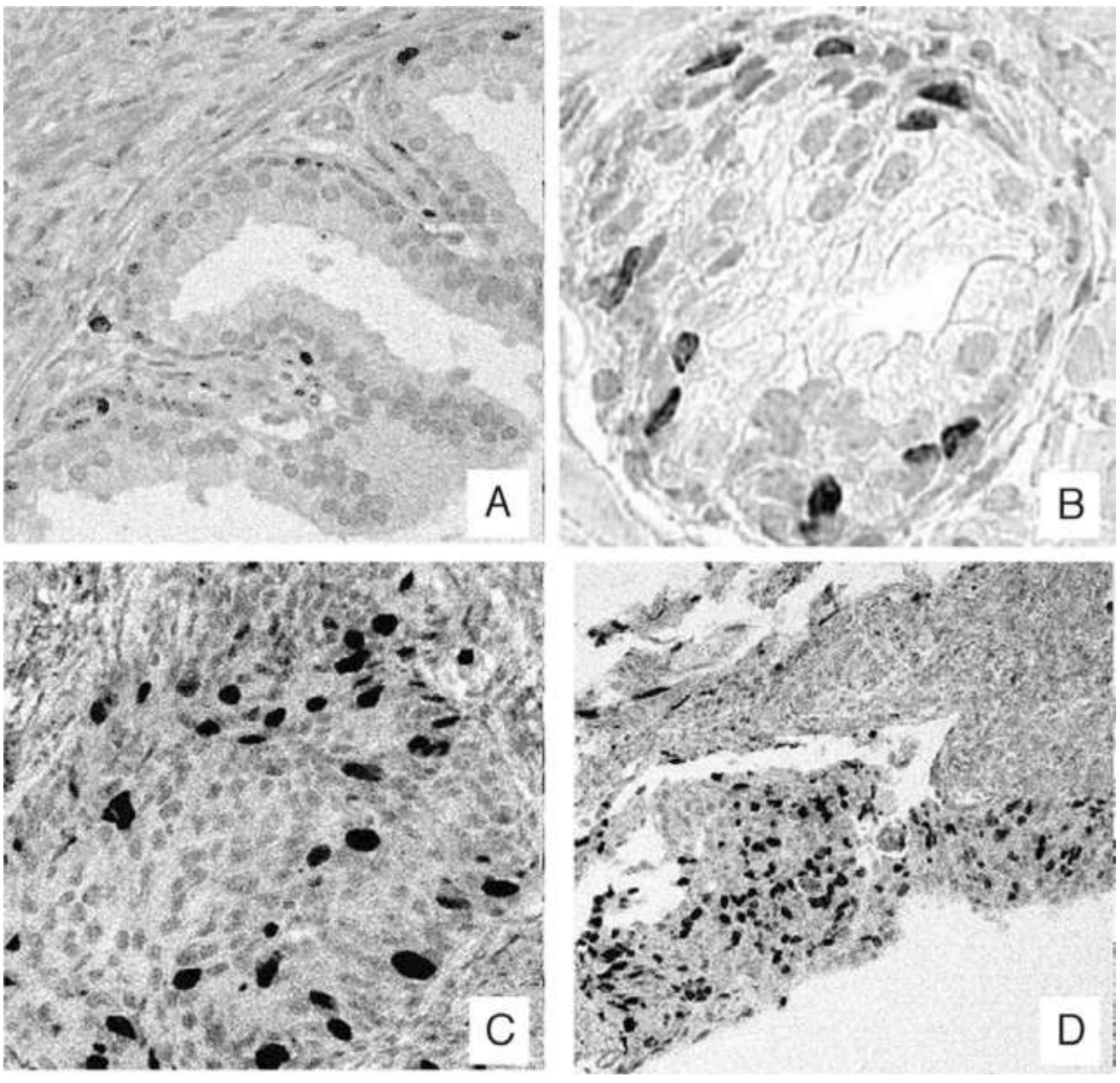

Figure 1. Immunolabeling for Ki-67 in pre-malignant and malignant lesions of the prostate. A: LGPIN, presenting weak (+), diffuse positivity in cells of the basal layer. (Magnification power 10×) B: HGPIN, presenting weak positivity (+) in cells of the basal layer and the luminal layer of the epithelium. (Magnification power $40 \times$ ) C: Carcinoma of prostate presenting moderate positivity (++). (Magnification power 20×). D: Carcinoma of prostate presenting intense positivity (+++). (Magnification power 10×).

\section{Discussion}

The predictive value of the labeling index by Ki-67 has special importance in the types of cancers in which it is difficult to predict the clinical course solely by histological criteria. There are numerous studies that analyze this predictive value in carcinoma of the prostate, although there is a great vari- ability of results. Thus, an international standardization of the labeling methods and clinical morphological validation through multi-central and randomized prospective studies is urgently needed, (Scholzen and Gerdes, 2000), so as to obtain a consensus from all points of view (Bostwick et al., 2000).

In this study on evaluating the immunolabeling of 
Table 1. Results obtained with the immunolabeling for Ki-67 in biopsies of prostate according to histological diagnosis.

\begin{tabular}{lcccc}
\hline \hline & $\begin{array}{c}\text { BPH } \\
(N=49)\end{array}$ & $\begin{array}{c}\text { LGPIN } \\
(N=53)\end{array}$ & $\begin{array}{c}\text { HGPIN } \\
(N=22)\end{array}$ & $\begin{array}{c}\text { CARCINOMA } \\
(N=35)\end{array}$ \\
\hline NEGATIVE & $4(8.2 \%)$ & $2(3.8 \%)$ & $2(8.0 \%)$ & 0 \\
POSITIVE $(+)$ & $42(85.7 \%)$ & $43(81.1 \%)$ & $18(72.0 \%)$ & $8(22.8 \%)$ \\
POSITIVE $(++)$ & $2(4.1 \%)$ & $8(15.1 \%)$ & $5(20.0 \%)$ & $22(62.9 \%)$ \\
POSITIVE $(+++)$ & $1(2.0 \%)$ & 0 & 0 & $5(14.3 \%)$ \\
\hline
\end{tabular}

Table 2. Qualitative evaluation of the presence of Ki-67-positive cells in the luminal layer of the prostate epithelium in non-invasive lesions.

\begin{tabular}{lccc}
\hline \hline & $B P H(N=49)$ & LGPIN $(N=53)$ & HGPIN $(N=25)$ \\
\hline NEGATIVE & $39(79.6 \%)$ & $31(58.5 \%)$ & $3(12.0 \%)$ \\
POSITIVE & $10(20.4 \%)$ & $22(41.5 \%)$ & $22(88.0 \%)$ \\
\hline
\end{tabular}

Ki-67 in different proliferative lesions, we have observed how the labeling for $\mathrm{Ki}-67$ in CAR is more intense than in the rest of the lesions studied. This result again demonstrates that the labeling index in CAR is more important than in the other benign or pre-malignant proliferative lesions. Nevertheless, we have not found significant differences between the Gleason's scores and the immunolabeling of $\mathrm{Ki}$ 67.

The expression of this proliferative label has also been detected in PIN and compared with benign prostate epithelium. This expression was more intense in HGPIN lesions and similar to that observed in invasive adenocarcinoma (Montironi et al., 1993). This supports the hypothesis that HGPIN represents an intermediate stage in the neoplastic transformation of the prostate epithelium. Equally, in studies of cell kinetics, a rank order among $\mathrm{BPH}, \mathrm{AAH}$ (atypical adenomatous hyperplasia), low grade carcinoma, PIN and high grade carcinoma has been established, considering PIN as a pre-neoplastic lesion (Helpap, 1995)

Moreover, the use of antibodies to the antigens associated with proliferation permits the study of the proliferative cells within specific compartments of a tissue. Thus, within the normal prostate epithelium, the majority of the cells immunoreactive for
Ki-67 are of the phenotype of basal cells, but in the HGPIN lesions, only 6-10\% of the immunolabeled cells are located in this layer, with a concomitant increase in the immunologically labeled dysplasic luminal cells (Myers, 1997). For this reason it has been suggested that, in PIN lesions, the luminal cells also acquire a proliferative potential.

Our results support this hypothesis, and in accordance with them, Ki-67 must be analyzed in different ways in invasive and non-invasive lesions.

In non-invasive proliferative lesions of the prostate, and in view of our data, the global analysis of Ki-67 does not seem to be very important. Indeed, it is logical that benign proliferative lesions will present an increase in labeling for $\mathrm{Ki}-67$ although it is clear that many of them will never evolve to malignancy. The study of $\mathrm{Ki}-67$ in the differentiated cells of the luminal layer of the prostate epithelium appears more interesting. In these cells we found significant differences, both when we analyzed all the groups of lesions together, or when compared one with another in pairs.

The presence of $\mathrm{Ki}-67$ in an epithelial layer where the cells should be differentiated (the luminal layer) could be useful as a prognostic factor since in our study there is an evident increase of the number of immunopositive cases in accordance with the increase of grade of histological lesion, the greater percentage being found in the HGPIN lesions.

We consider that additional studies with anti-Ki67 and 34BE12 antibodies, and DNA instability tests (Hirai et al., 2001; Iwasa et al., 2001) are required to quantify the proliferation fraction in the luminal layer of this type of lesion and its correlation with the clinical evolution. In the future, the pre-therapeutic management of the expression of $\mathrm{Ki}-67$ in the luminal compartment of HGPIN lesions could be important in the evaluation of the aggressiveness of these lesions and, as a result, in the selection of the proper treatment.

\section{Acknowledgements}

We would like to thank Mr. G.H. Jenkins for revising the English version of the manuscript.

\section{References}

Aaltomaa S, Lipponen P, Vesalainen S, Ala-Opas M, Eskelinen M, Syrjänen K. Value of Ki-67 immunolabeling as a prognostic factor in prostate cancer. Eur Urol 1997;32:410-5.

Bai XZ, Masters JR, O’Donoghue N, Kirby R, Pan LX, Young M, et al. Prognostic markers in clinically localised prostate cancer. Int $\mathrm{J}$ Oncol 1999; 14:785-91. 
Bettencourt MC, Bauer JJ, Sesterhenn IA, Mostofi FK, McLeod DG, Moul JW. Ki-67 expression is a prognostic marker of prostate cancer recurrence after radical prostatectomy. J Urol 1996;156:10648.

Boring CC, Squires TS, Tong T, Montgomery S. Cancer statistics, 1994. Cancer J Clin 1994;44:7-26.

Borre M, Bentzen SM, Nerstom B, Overgaard J. Tumor cell proliferation and survival in patients with prostate cancer followed expectantly. J Urol 1998;159:1609-14.

Bostwwick DG, Grignon DJ, Hammond ME, Amin MB, Cohen M, Crawford D, et al. Prognostic factors in prostate cancer. College of American Pathologists consensus statement 1999. Arch Pathol Lab Med 2000;124:995-1000.

Brown C, Sauvageot BS, Kahane $\mathrm{H}$, et al. Cell proliferation and apoptosis in prostate cancer: correlation with pathologic stage? Mod Pathol 1996;9:205-9.

Budenfort L, Sauter G, Moch H, Schmid HP, Gasser TC, Jordan P, et al. ki-67 labeling index: an independent predictor of progression in prostate cancer treated by radical prostatectomy. J Patho 1996:178:437-41.

Cher ML, Stephenson RA, James BC, Carroll PR. Cellular proliferative fraction of metastatic lymph nodes predicts survival in stage DI (TxN+MO) prostate cancer. J Urol 1996;155:1674-7.

Cohen RJ, McNeal JE, Baillie T. Patterns of differentiation and proliferation in intraductal carcinoma of the prostate: significance for cancer progression. Prostate 2000;43:11-9.

Frankel KA. Intraepithelial melanocytic neoplasia: a classification by pattern analysis of proliferation of atypical melanocytes. Am J Dermatopathol 1987;9:80.

Helpap B. Cell Kinetic studies on prostatic intraepithelial neoplasia (PIN) and atypical adenomatous hyperplasia (AAH) of the prostate. Pathol Res Pract 1995;191:904-7.

Hepburn PJ, Glynne-Jones E, Goddard L, Gee JM, Harper ME. Cell proliferation in prostatic carcinoma: comparative analysis of Ki-67, MIB-1 and PCNA. Histochem J 1995;27:196-203.

Hirai K, Kumakiri M, Ueda K, Imamura Y, Noriki S, Nishi Y, et al. Clonal evolution and progression of 20-methylcholanthrene-induced squamous cell carcinoma of mouse epidermis as revealed by DNA instability and other malignancy markers. Eur J Histochem 2001;45:319-32.

Iwasa M, Imamura $Y$, Noriki S, Nishi $Y$, Kato H, Fukuda M. Immunohistochemical detection of early-stage carcinogenesis of oral leukoplakia by increased DNA-instability and various malignancy markers. Eur J Histochem 2001;45:333-46.

Keshgegian AA, Johnston $E$, Cnaan A. Bcl-2 oncoprotein positivity and high MIB-1 (Ki-67) proliferative rate are independent predictive markers in prostate carcinoma. Am J Clin Pathol 1998;110:443-9.

Lowell WR. Carcinoma in situ. In: Page DL, Anderson TJ, Eds. Diagnostic histopathology of the breast. New York: Churchill-Livingstone; 1987. p. 157.

Montironi R, Galluzzi CM, Diamanti L, Giannulis I, Pisani E, Scarpelli M. Prostatic intraepitelial neoplasia: Expression and localization of proliferating cell nuclear antigen (PCNA) in epithelial, endothelial and stromal nuclei. Virchows. Arch 1993;422:185-92.

Moul JW, Bettencourt MC, Sesterhenn IA, Mostofi FK, McLeod DG, Srivastasa $\mathrm{S}$, et al. Protein expression of $\mathrm{p53}, \mathrm{bcl}-2$, and $\mathrm{Ki}-67$ (MIB-1) as prognostic biomarkers in patients with surgically treated, clinically localized prostate cancer. Surgery 1996;120:159-66.

Myers RB, Grizzle WE. Biomarker expression in prostatic intraepithelial neoplasia. Eur Urol 1996;30:153-66.

Rywlin AM. Intraepithelial melanocytes neoplasia (IMN) versus intraepithelial atypical melanocytic proliferation (IAMP). Am J Dermatopathol 1988; 10:92.

Scholzen T, Gerdes J. The Ki-67 protein: from the know and the unknow. J Cell Physiol 2000;182:311-22.

Stapleton AM, Zbell P, Kattan MW, Yang G, Wheeler TM, Scardino PT, et al. Assessment of the biologic markers p53, Ki-67, and apoptotic index as predictive indicators of prostate carcinoma recurrence after surgery. Cancer 1998;82:168-75.

Tavassoli FA, Norris HJ. A comparison of the results of long-term follow-up for atypical intraductal hyperplasia and intraductal hyperplasia of the breast. Cancer 1990;65:518.

The 1988 Bethesda System for reporting cervical/vaginal cytological diagnoses. National Cancer Institute Workshop. JAMA 1989;262: 931-4. 
E. Muñoz et al. 